\title{
Trajetórias intelectuais marcadas entre a ciência e a religião: José Loureiro Fernandes e a Faculdade de Filosofia, Ciências e Letras do
} Paraná

\author{
PAULO GUÉRIOS
}

\begin{abstract}
A carta
Prezado Prof. Pe. Luigi Castagnola

Recebi sua carta no dia seguinte ao de outra recebida do longínquo sul, a qual, dirigida por um velho jesuíta, me preocupou apenas pelo escândalo que se quer emprestar à minha atitude afastando-me do que chamam "grupo militante católico apostólico romano" nas hostes do Cristianismo. Poderia tomar a atitude cômoda de tantos outros, continuando católico por tradição, (...) mas, porventura, não tenho o direito de ser coerente comigo mesmo?

Não quero nesta resposta levantar questões, mas tenho de repelir afirmativas suas ou erros de interpretação de minhas palavras a bem da Verdade: não há para mim crise religiosa; o que o senhor chama angústia religiosa e sofrimento espiritual são coisas do passado, foram elas que durante anos levaram-me lentamente à minha situação atual - situação de 'tranquilidade espiritual', situação definida para a qual o senhor, tão bondosamente, ainda esperava contribuir. Como vê, toda esta evolução (se Vossa Reverendíssima quiser crise) é coisa superada, e para tal foi necessária muita fortaleza de espírito, para poder abandonar consciente, já com meio século de vida, e portanto mais perto da morte, hábitos de consciência religiosa adquiridos desde a infância como resultado de uma educação recebida no seio de família católica apostólica romana. (...) Guardei uma confiança imensa na obra do Cristo e meu desejo ora avante, se é não perturbar a fé dos outros, é também de que os demais não perturbem a serenidade de minhas convicções religiosas. (...)

No meu comentado discurso de paraninfo, o que houve? - O senhor mesmo reconheceu - uma definição de minha parte, a repetição de certas verdades, verdades olhadas com objetividade científica e não ao sabor sectário de certos diretores e supostos mentores da grei universitária. (...) Nunca
\end{abstract}


aceitei o extremado sectarismo de alguns homens da Igreja romana - tão chocante com o espírito de fraternidade pregado pelo Cristo (...).

Atenciosamente seu servo em Cristo,

José Loureiro Fernandes ${ }^{1}$

Esta foi a resposta escrita de José Loureiro Fernandes, catedrático de Antropologia da Faculdade de Filosofia, Ciências e Letras do Paraná (FFCLPR), à carta que lhe foi endereçada pelo padre Luigi Castagnola - recém aprovado, em abril de 1955, no concurso para a cátedra de Língua e Literatura Italianas da mesma Faculdade. A carta original de Castagnola foi enviada logo após Loureiro Fernandes ter se unido àqueles que questionaram o resultado do concurso; é possível depreender que sua atitude foi entendida pelos membros do autorreferido "grupo militante católico apostólico romano" como uma crise de "angústia religiosa e sofrimento espiritual". Loureiro repele essa possibilidade, dizendo ter finalmente encontrado sua "tranquilidade espiritual".

A carta de Loureiro, no entanto, carrega grande ambiguidade. Logo após afirmar ter abandonado "hábitos de consciência religiosa adquiridos desde a infância", ele diz ter guardado "uma confiança imensa na obra do Cristo"; o esforço de "repelir afirmativas suas ou erros de interpretação de minhas palavras a bem da Verdade" é feito a partir do confronto de tais afirmativas com "verdades olhadas com objetividade científica"; o "direito de ser coerente consigo mesmo", enfim, parece cindido entre a Verdade espiritual de sua fé e as verdades de sua formação científica. Castagnola, em tréplica acusatória e carregada de ressentimento, escreve-lhe apenas afirmando estar agora "ciente de que o doutor Loureiro não é mais católico" ${ }^{2}$ reação que parece apenas enquadrá-lo no "extremado sectarismo de alguns homens da Igreja romana - tão chocante com o espírito de fraternidade pregado pelo Cristo".

Essa controvérsia foi parte do que, em obra comemorativa dos 50 anos de fundação da FFCLPR, a professora Cecília Westphalen (1988: 40 a 43), catedrática de História da Faculdade, qualificou como os "anos tumultuados" por que a instituição passou entre 1955 e 1959. Os desentendimentos que, a seu ver, romperam a "unidade e a coesão" da Faculdade iniciaram-se justamente com a querela acerca do concurso de Castagnola. A FFCLPR tinha sido fundada em 1938 enquanto instituição privada, e, em um estado que não tinha recursos para a contratação de professores estrangeiros como ocorreu em São Paulo, teve seu corpo de professores composto por intelectuais locais, convidados pelos fundadores para ocupar as diferentes cátedras. Em 1955, a FFCLPR já tinha sido incorporada à recém-federalizada Universidade Federal do Paraná, e o preenchimento das cátedras apenas poderia ser feito a partir de um concurso público de títulos e provas. A Congregação da Faculdade, no entanto, tinha a prerrogativa de conceder títulos de notório saber, que permitiam a agregação de candidatos ao posto de catedrático na qualidade de livres docentes. Padre Castagnola, que atuara como assistente de ensino da disciplina de Introdução à Filosofia na FFCLPR em 1951 (Prado 2017: 98), era formado em Filosofia e Teologia na Itália, mas não possuía titulação na área de Língua e Literatura, objeto da cátedra. A Congregação da Faculdade concedeu-lhe o notório saber na área, viabilizando sua inscrição para o concurso.

1 Arquivo do Círculo de Estudos Bandeirantes, DOC551. Neste artigo, as referências a fontes primárias serão indicadas nas notas.

2 Arquivo do Círculo de Estudos Bandeirantes, DOC548. 
Castagnola teve, contudo, um concorrente que possuía a titulação exigida: Bruno Enei, formado em Língua e Literatura na Itália com Attilio Momigliano - um "prolífico e influente crítico literário" (Hainsworth e Robey 2005). Com a aprovação de Castagnola, Enei protocolou um recurso questionando a composição da banca examinadora logo após o resultado, em 15 de abril de 1955. Logo a seguir, Loureiro Fernandes e Wilson Martins, catedrático de Língua e Literatura Francesa, propuseram à Congregação da Faculdade uma regulamentação geral da matéria relativa à concessão de títulos de notório saber (Westphalen op cit: 40), explicitando uma divisão interna no corpo da Faculdade que viria a aprofundar-se após terem sua proposta negada em votação.

Os conflitos que ocorreram como desdobramentos desse acontecimento acabaram por ter uma repercussão nacional, que foi estudada em pormenores por Valéria Machado em sua tese de doutoramento (Machado 2009). A polêmica, inicialmente restrita aos círculos internos da Faculdade, foi trazida a público em artigos publicados por Paulo Duarte, um dos fundadores da Universidade de São Paulo, em sua revista Anhembi - um "foro avançado de combate (...) nas lutas por espaço no processo de modernização cultural em curso em São Paulo" (Miceli 1989b:24). No número publicado em junho de 1955, Duarte escreveu um manifesto em defesa de Enei afirmando que o "faccionismo" do então diretor da FFCLPR, Homero de Barros, "impedia a inscrição e a aprovação de candidatos que não fizessem parte do seu grupo religioso" (apud Machado op cit: 24). Duarte ressaltou que a própria Faculdade tinha possibilitado a participação de Castagnola no concurso ao conceder-lhe um título de notório saber em uma área que não era de sua especialidade, compondo posteriormente uma banca composta por amigos pessoais do religioso. Outras denúncias se seguiram nas páginas de Anhembi nos anos de 1958 e 1959, incluindo: a exclusão da revista do acervo da biblioteca da Faculdade; a retirada de títulos da biblioteca contrários à orientação religiosa da Direção, assim como o impedimento de acesso dos alunos a certos livros e a mutilação de obras anticlericais; e a manipulação das eleições à direção da Faculdade, em manobras políticas que perpetuavam Homero de Barros no cargo (op cit: 25 a 29). Os casos tiveram ainda maior divulgação após serem objeto de reportagem da revista O Cruzeiro, a publicação de maior circulação no país, na época, com tiragem calculada em torno de dois milhões de exemplares (op cit: 41 ).

A partir do emprego da noção de campo, de Pierre Bourdieu, Machado busca demonstrar que, para além da administração da FFCLPR, estavam em jogo as disputas que ocorriam no Brasil acerca da configuração do campo intelectual e do sistema escolar brasileiros, marcados desde a década de 1920 por embates entre grupos católicos e grupos pautados por ideais seculares:

as polêmicas geradas em torno do 'caso Bruno Enei' podem ser percebidas como uma das primeiras manobras efetuadas pelos agentes interessados em instituir a racionalidade [e] a objetividade acadêmica no processo de seleção para as cátedras - nas quais a especialização seria um dos princípios que garantiriam credibilidade. (...) As tensões não eram novas porque as necessidades de mudanças estruturais já haviam colocado em confronto as elites letradas laicas - que se identificavam com a racionalidade inerente ao processo de modernização - e os grupos dominantes mais conservadores - que se apoiavam nas bases religiosas do catolicismo para manter o controle das instituições (op cit: 177, 178). 
A partir da década de 1920, Loureiro Fernandes tinha estado à frente das iniciativas de criação de instituições culturais e educacionais levadas a cabo pela rede de intelectuais católicos paranaenses. Em agosto de 1924, ele foi um dos fundadores do Grêmio Literário São Luiz, "ligado à Congregação Mariana dos Jovens da Catedral, [que] tinha como objetivo 'incrementar entre os jovens o amor aos estudos e estimular o gosto pelas letras', como também propagar a fé católica, defender os dogmas da Igreja e militar em defesa da família, da Pátria e de Deus" (Hanicz 2006: 206). Seu nome não aparece entre os membros presentes à criação da União dos Moços Católicos de Curitiba, realizada em agosto de 1926 em uma das salas do Convento dos padres Franciscanos (op cit: 83), visto que neste ano ele cursava Medicina no Rio de Janeiro; mas, logo após retornar a Curitiba, ele foi membro fundador do Círculo de Estudos Bandeirantes (CEB), polo de concentração da rede local de intelectuais leigos ligados ao catolicismo, cujas reuniões ocorreram a partir de 1929 no porão de sua casa. O CEB foi fundamental para a constituição da própria FFCLPR. Quando professores das Faculdades de Medicina, Engenharia e Direito mobilizaram-se para criar uma Faculdade de Filosofia em Curitiba em 1938 visando à restauração da Universidade do Paraná, ${ }^{3}$ boa parte da intelectualidade local participava das reuniões do CEB; o convite inicial para a contratação de catedráticos levou o corpo docente da Faculdade a contar com 16 membros do CEB entre seus 40 componentes em 1941 (Furtado 2000: 60). Quando da insolvência financeira da Faculdade, já em seu segundo ano de funcionamento, foi novamente Loureiro Fernandes quem articulou a participação da União Brasileira de Educação e Ensino, pertencente aos Irmãos Maristas, como mantenedora da Faculdade, assegurando sua sobrevivência (Glaser 1988: 9).

A centralidade da participação de Loureiro Fernandes nesta rede de intelectuais ligados à Igreja Católica no Paraná permite que entendamos a intensidade das cobranças feitas sobre ele quando se opôs à contratação de Castagnola e à disseminação da distribuição de títulos que garantiam a presença de membros da rede na FFCLPR. Mas o que sua carta a Castagnola indica é que ele não entendia participar de um "grupo militante católico", termo que aparece ali entre aspas.

O presente artigo tem o objetivo de problematizar as discussões acerca das dinâmicas de funcionamento dessa rede de intelectuais paranaenses da FFCLPR ligados ao catolicismo. Como vimos, essa rede se estendia para muito além dessa instituição, e assim, ao estudá-la, teremos acesso a indicativos que podem permitir repensar de modo mais amplo os processos sociais envolvidos na constituição das instituições culturais e universitárias brasileiras na primeira metade do século XX. Para cumprir esse objetivo, tomaremos como eixo elementos da trajetória pessoal de Loureiro Fernandes, partindo da

3 Campos (2008: 151) entende que proposta de criação da FFCLPR partiu dos membros das faculdades tradicionais porque elas viam a presença de uma Faculdade de Filosofia como um elemento que daria força ao projeto de restauração da Universidade do Paraná, criada enquanto Universidade em 1912 mas separada em suas Faculdades componentes (Direito, Engenharia e Medicina) em 1915 devido à Lei Maximiliano. Essa compreensão é expressa por um dos membros da Faculdade de Engenharia à época, Ildefonso Puppi, que afirma que "a convicção [do grupo] era de que o objetivo [da restauração da Universidade do Paraná] seria mais facilmente alcançado se viesse a ser criada uma Faculdade de Filosofia, Ciências e Letras, para, incorporando-se às três existentes, constituir-se o núcleo de agregação. Logo a seguir, era instaurada essa unidade considerada de importância fundamental (...)" (Fatos e reminiscências da Faculdade, obra editada pela FUNPAR em 1986, p. 42). Ainda segundo Campos (2008: 153), o "laicato católico paranaense" ainda não tinha tomado a iniciativa de criar uma Faculdade de Filosofia porque "aguardava orientações do episcopado brasileiro para criação de faculdades católicas. No entanto, a criação da FFCL em Curitiba, pensada por Homero Braga e Gonçalves da Mota, acelerou esse processo, forçando a Igreja Católica a estabelecer aquela instituição no Paraná, precedendo à experiência carioca, onde se encontravam as principais lideranças do laicato católico brasileiro". 
ambiguidade expressa em sua carta a Castagnola. E se desejamos compreendê-la, teremos que voltar no tempo, explorando os projetos da Igreja a que Loureiro se vinculou e sua participação nas redes que ajudou a compor.

\section{A encíclica}

É pela filosofia (...) que o espírito dos fiéis do Cristo se deixa mais frequentemente enganar, e que a pureza da fé se corrompe entre os homens. (...) Hoje, a importância do assunto e as circunstâncias nos conduzem a tratar novamente da natureza de um ensino filosófico que respeite ao mesmo tempo as regras da fé e a dignidade das ciências humanas. (...)

A causa dos males que nos afligem, assim como daqueles que nos ameaçam, consiste em que opiniôes equivocadas sobre as coisas divinas e humanas se insinuaram aos poucos nas escolas de filosofia. (...) Mas nós não devemos desprezar nem negligenciar os auxílios naturais colocados ao alcance dos homens pela sabedoria divina (...), e, de todos esses auxílios, o mais poderoso, sem dúvida, é o uso correto da filosofia. (...) É dela que a teologia sagrada deve receber e revestir a natureza, a forma e o caráter de uma verdadeira ciência. (...)

Os doutores da idade média, conhecidos pelo nome de escolásticos, realizaram uma obra colossal (...) Entre todos os doutores escolásticos, brilha o príncipe e mestre de todos, Tomás de Aquino.

(...) Ao mesmo tempo em que ele distingue perfeitamente, como convém, a razão da fé, ele as une por laços de amizade mútua: ele conserva assim os direitos de cada uma, ele preserva sua dignidade, de modo que a razão, carregada sobre as asas de são Tomás até o topo da inteligência humana, não pode subir mais alto, e que a fé não pode esperar da razão garantias mais numerosas ou poderosas do que aquelas que são Tomás forneceu. (...)

[Mas] no lugar da doutrina antiga, um novo gênero de filosofia se introduziu aqui e ali, e não trouxe os frutos desejáveis e saudáveis que a Igreja e a própria sociedade civil teriam desejado. Sob o impulso dos inovadores do século XVI, colocaram-se a filosofar sem qualquer respeito pela fé e permitiu-se uma liberdade plena de deixar seu pensamento derivar seguindo seus caprichos e seu gênio (...) produzindo uma filosofia raquítica e sem consistência. (...)

É assim por uma feliz inspiração que numerosos amigos das ciências filosóficas desejosos, nesses últimos anos, de levar a cabo a restauração de um modo eficaz, aplicaram-se e aplicam-se a recolocar em vigor a admirável doutrina de Tomás de Aquino. (...) O imenso perigo ao qual o contágio de falsas opiniões relegou a família e a sociedade é para nós evidente. Certamente ambas gozariam de uma paz mais perfeita e de uma maior segurança se, nas universidades e nas escolas, fosse abordada uma doutrina mais sã e mais conforme aos ensinamentos da Igreja, uma doutrina como a encontrada nas obras de Tomás de Aquino. ${ }^{4}$

Os trechos acima citados da encíclica Aeterni Patris, promulgada por Leão XIII em 1879, constituem o programa filosófico que a Igreja Católica buscou implementar a partir de então em reação ao que percebia como um esvaziamento da fé católica e de sua influência no mundo temporal. $\mathrm{O}$ foco da transformação aí buscada era construir e difundir uma atitude intelectual que revertesse as mudanças causadas pelas transformações nas doutrinas filosóficas desde o Renascimento. Tratava-se, como sub-

4 Tradução livre realizada a partir do texto da encíclica Aeterni Patris em versão francesa, que pode ser consultado em http://w2.vatican. va/content/leo-xiii/fr/encyclicals/documents/hf 1-xiii enc 04081879 aeterni-patris.html. Acesso em 30 de março de 2018. 
linha o texto papal, de fomentar e disseminar a produção de uma filosofia e de uma ciência do homem que não se chocassem com as "regras da fé", e que esclarecessem como a fé e a filosofia poderiam alimentar uma à outra. O caminho dessa restauração da "doutrina antiga" seria dado pela obra de São Tomás de Aquino, filósofo católico escolástico do século XIII que defendia o uso da razão e da argumentação para atingir o conhecimento de Deus e de suas obras. O objetivo desse esforço, assim, era reconstituir a centralidade do pensamento filosófico cristão no mundo contemporâneo através da própria Ciência, que se firmava como uma das marcas centrais da modernidade - mas buscando subsumir a segunda sob o primeiro, ao resgatar o caráter transcendental do pensamento filosófico e negar a imanência do saber humano (marca do "modernismo" filosófico)5. O pensamento de Aquino deveria assim substituir aquele dos "inovadores" como Descartes, Hegel e Kant, cujas filosofias, derivadas de "seus caprichos e seus gênios" individuais, não guardavam "qualquer respeito pela fé" e se mostravam, assim, "raquíticas" e "sem consistência".

Nos anos finais do Império, a Igreja Católica estava se reestruturando no Brasil. Até então, ela era submetida ao poder civil devido à instituição do padroado, segundo o qual os reis de Portugal, "em decorrência de privilégios recebidos do Papa, se tornavam uma espécie de legados plenipotenciários com deveres e poderes para implantar e dilatar a religião católica no Brasil” (Hanicz 2006: 116). Ainda no período imperial, o padroado brasileiro foi colocado em questão por vários motivos, dentre eles o início de um processo de questionamento interno de membros da Igreja acerca de seu afastamento em relação à fé e seu envolvimento com o poder civil, e os ataques da Igreja à maçonaria, instituição da qual participava o imperador Dom Pedro II. Apoiados pelo Papa Pio IX, os bispos Dom Vital e Dom Macedo Costa deram impulso a um movimento de "restauração" dentro da Igreja, buscando primeiramente dar formação e "elevar o nível espiritual e cultural do clero", distanciando os sacerdotes da vida mundana e política (op cit: 119). Nas palavras de Miceli (1985: 177), a Igreja brasileira passou então por um período de "construção institucional", buscando "viabilizar-se como empreendimento religioso e como organização burocrática”.

Esse processo envolveu um esforço para transformar o catolicismo leigo, que se organizava em Associações e Irmandades dedicadas às obras de assistência aos pobres e à devoção. Essas instituições funcionavam como um misto de associação político-civil e religiosa, estabelecendo uma relação com a religião que dispensava a presença e a direção do clero. Seus membros, pertencentes às elites urbanas, tinham contato íntimo com ideias modernas, como o liberalismo, a maçonaria e o positivismo. O processo de restauração logrou alterar esse perfil do laicato católico, que "se [deslocou] da esfera das devoções e associações e se [direcionou] para a esfera da cultura e da intelectualidade, porém em harmonia com a hierarquia eclesiástica e com a tradição católica romana” (Hanicz 2006: 128 a 131).

5 Miceli (1985: 32) marca a ligação desse projeto doutrinário com a consolidação dos estados-nação na Europa, incluindo a unificação da Itália em 1870, o que afetou diretamente o Vaticano e as pretensões da Igreja a manter-se em íntima conexão com o poder político na Europa. O "modernismo" repudiado pela Igreja desde o século XIX, assim, abrangia não apenas as diferentes escolas filosóficas, mas toda a estruturação da sociedade contemporânea. A encíclica Quanta Cura, promulgada por Pio XI em 1864, era acompanhado do Syllabus Errorum, "um catálogo de 80 erros condenados pela Igreja e que deveriam ser rejeitados pelos católicos" (Hanicz 2006: 101). Dentre os "erros modernos" estavam assim "o racionalismo, o socialismo, o comunismo, a maçonaria, a separação entre a Igreja e o Estado, as liberdades de imprensa, de religião, em suma, 'o progresso, o liberalismo e a civilização moderna” (Miceli op. cit.). 
As novas instituições intelectuais do laicato católico constituíram o polo de divulgação e disseminação da neoescolástica tomista no Brasil. Sua origem é ligada às ações de Dom Leme, bispo de Olinda e Recife. Em 1916, Dom Leme havia escrito uma Carta Pastoral na qual apontava as deficiências e a pouca influência da Igreja na sociedade brasileira, devida especialmente, para ele, à ignorância religiosa: "aos nossos irmãos falta a instrução religiosa necessária para enfrentarem com vantagem as investidas da incredulidade (...). Conhecimentos religiosos, precisos, claros, fundamentados, em geral, não os têm. É um mal" (apud Hanicz, op cit: 174). As ideias de Dom Leme inspiraram intelectuais cariocas a criarem a revista A ordem, e, a partir dela, o Centro Dom Vital, que seria o ponto de referência do laicato católico brasileiro - especialmente após sua direção ter sido assumida pelo intelectual Alceu Amoroso Lima, em 1928.

No Paraná, o processo de restauração da Igreja iniciou-se com a criação de uma Diocese em 1892. Como demonstra Miceli (1985: 44, 45), a estadualização da estrutura organizacional da Igreja ecoou as tendências descentralizadoras do regime republicano, que concedeu maior autonomia às oligarquias locais. Nos estados em que as diretrizes católicas encontravam receptividade entre a população e apoio das oligarquias e dos setores dirigentes - Miceli cita especificamente Minas Gerais - os bispos conseguiam restaurar a influência da Igreja, seguindo as políticas estabelecidas pelo Vaticano. Dentre os indicativos do sucesso de suas ações estiveram a eleição de políticos sintonizados com as demandas da Igreja, o apoio estatal para a construção de paróquias e sedes diocesanas, e, como ponto fundamental dessa política, a criação de escolas religiosas e associações leigas (op cit: 69 a 71). O mesmo ocorreu no Paraná: o bispo dom João Francisco Braga contou com o apoio do Estado para construir o seminário diocesano em 1894, e ainda em 1925 o presidente do Estado, Caetano Munhoz da Rocha, cedeu recursos públicos para construir as sedes das novas dioceses nas cidades de Ponta Grossa e Jacarezinho (Hanicz, op cit: 181). Dom João criou igualmente condições para a vinda de várias ordens religiosas ao Paraná, o que resultou na criação de vinte colégios religiosos no estado, como o dos Irmãos Maristas (Santa Maria), o dos franciscanos (Bom Jesus) e o Ginásio Diocesano, "onde estudava a elite da mocidade paranaense" (op cit: 179). Dessas instituições surgiu uma nova geração de leigos católicos, que seriam convidados a criar e participar de organizações juvenis como aquelas de que Loureiro Fernandes fez parte - o Grêmio São Luís, a União dos Moços Católicos de Curitiba, e, por fim, o Círculo de Estudos Bandeirantes (CEB).

O CEB, criado em 1929 por Loureiro Fernandes e por José Farani Mansur Guérios a pedido do padre lazarista Luís Gonzaga Miele, foi, como afirmamos acima, a instituição cultural que congregou os membros do laicato católico em Curitiba. O objetivo do CEB seguia as diretrizes de Dom Leme. A Ata do primeiro encontro relata que Miele indicou ali a "necessidade de centralizar e conglobar esforços e valores esparsos, a fim de todos participarem da permuta de ideias e intercâmbio do pensamento orientador das almas, que se devem enrijar na escola do caráter inflexível, do dever e da responsabilidade sociais, em face da anarquia reinante no mundo das inteligências" (apud Hanicz, op cit: 212). A instituição buscava, assim, congregar os intelectuais curitibanos simpáticos à Igreja e dar-lhes "instrução para enfrentar as investidas da incredulidade”. Dentre os membros do Círculo, é possível constatar 
a presença de juristas, desembargadores, médicos, engenheiros, músicos, comerciantes e industriais (cf. Ferrarini 2011).

Os encontros do CEB, cujos conteúdos eram sempre registrados em atas e por vezes publicados em uma Revista editada pela própria instituição, seguiam o método de instrução escolástica: ${ }^{6}$ um membro do grupo era convidado previamente para dissertar sobre um tema de sua especialidade (a lectio). Antes de qualquer pergunta, a sessão era interrompida por alguns minutos, para que os outros membros refletissem sobre o que ouviram (medidatio). Após o intervalo, os participantes colocavam perguntas que lhes tinham ocorrido (quaestio) e ocorriam as discussões (disputationes), que buscavam resolver as questões que se mostrassem controversas. Eventuais proposições contraditórias que ficassem em aberto voltavam a ser colocadas em questão em uma reunião posterior, apresentadas pelo instrutor (ao longo dos primeiros anos, o próprio padre Miele). O objetivo deste método era levar os participantes a considerar pontos de vista conflitantes e defender seus argumentos frente a eles.

Após alguns anos de discussões, os próprios membros do CEB decidiram buscar consolidar sua formação filosófica solicitando que um padre claretiano de origem espanhola, Jesus Ballarin, lecionasse um curso de Filosofia Tomista. O curso ocorreu entre maio de 1935 e dezembro de 1936 (Hanicz op cit: 248, 249). Pouco mais de um ano depois, como afirmado acima, vários membros do CEB foram convidados a participar do corpo de catedráticos da Faculdade de Filosofia, Ciências e Letras do Paraná. Era uma oportunidade para disseminar a formação tomista com a qual tinham tido contato em suas reuniões. Assim como esse foi o objetivo determinado institucionalmente para o CEB, esse foi o projeto que pautou, inicialmente, a presença desses intelectuais na Faculdade.

\section{O discurso aos bacharéis}

Dirigindo-se à primeira turma de bacharéis [em 1940] acentuava na sua oração de paraninfo o prof. Brasil Pinheiro Machado sermos 'todos combatentes da mesma batalha, perseguidores da mesma finalidade, que é a criação de um clima propício ao desabrochar de uma verdadeira liderança intelectual dentro do desordenado ambiente da cultura nacional' (...). Nas circunstâncias atuais do mundo, a função dessas elites intelectuais, carreadoras da verdadeira cultura, é sobrestimada como uma das forças líderes capazes de se contrapor à anarquia social (...) No desempenho da sua função cultural, abre a Faculdade de Filosofia novas e promissoras perspectivas, pois na ordem científica, ao conduzir a interpretação erudita dos fatos, vai desvendar às futuras gerações a nossa realidade e despertar a consciência nacional (...) para as nossas singularidades regionais, fazendo-a desvendar com a falência do 'ufanismo' e a perfeita interpretação da natureza íntima dos fatos, normas seguras e ritmos novos de ação. (...) Ficar-vos-á dessa luta travada na esfera na esfera serena das ideias a glória de ter podido atingir a verdade guiados pela luz da própria inteligência.

A perseverança no estudo consolidará a vossa personalidade, e ireis com dignidade e pessoal esforço forjar os brasões da vossa nobreza. Títulos nobiliárquicos que, para os cultores da Ciência, consistem em ser 'Confidentes do Criador, Ministros do Progresso e Sacerdotes da Verdade'.

Humilde confidente do Criador, só o verdadeiro cientista pode 'compreender algo dessa linguagem misteriosa que Deus escreveu na natureza. (...) Neste mesmo recinto ainda ecoam as palavras

6 Para uma descrição detalhada desse método, ver Rouwendal (2010: 59 a 62). 
do mestre insigne que é Alceu Amoroso Lima: 'Haverá sempre certa margem (...) entre a verdade em si e a nossa representação, que tornará sempre precárias as relações dos homens entre si e deles com os fenômenos da natureza. (...) Pois uma coisa é o nome que Deus deu [às coisas] e outra, muito diversa, o que nós outros lhes emprestamos. A Ciência, afinal, não é mais do que a procura, pelos homens, do nome que Deus deu às coisas do universo'. (...)

Vemos constituir-se no corpo docente e também no corpo discente desta Faculdade uma corrente de opinião para exigir (...) a obrigatoriedade do estudo da 'Introdução à Filosofia' para o primeiro ano de todas as Seções desta Faculdade. Merece a iniciativa (...) francos aplausos pois será uma advertência (...) contra os riscos do cientismo, que no seu 'culto exclusivo à ciência positiva vai à intransigência de afirmar que não há outra realidade além do mundo das sensações, das leis e dos objetos científicos'. Devemos substituir essa concepção de ciência (...) por aquela que 'compreende a ciência como conhecimento tanto dos fenômenos (ciências positivas) como da substância (ciência metafísica)'. E nesse sentido afirmou Alceu de Amoroso Lima: 'A metafísica é a mais real das ciências, pois estuda o ser concreto em toda a sua plenitude'. (...)

Parafraseando o Dr. Márcio Munhoz, diremos que 'será com esse espiritualismo, com essa orientação filosófica que a Faculdade de Filosofia terá de influir de maneira decisiva na formação mental da nossa mocidade. O Sacerdócio da Verdade, sagrado ministério, é que dá a esta Faculdade alta expressão intelectual ao traduzir um sentimento coletivo, uma corrente de opinião, um roteiro de atividades cujo objetivo é o de constituir uma verdadeira escola. ${ }^{7}$

Como esses trechos do discurso de Loureiro Fernandes aos formandos da turma de 1943 da FFCLPR deixam claro, o projeto do CEB estendeu-se para a Faculdade através dos membros desta que se tornaram catedráticos daquela. Em sua fala, a Ciência seria o guia seguro para o progresso da nação. E esta Ciência, a "verdadeira cultura", a "perfeita interpretação da natureza íntima dos fatos", não se restringiria ao "cientismo" do olhar positivista, pois o conhecimento apenas atingiria sua plenitude ao incorporar a esse saber o saber metafísico da filosofia católica.

Em sua tese de doutoramento, Névio de Campos (2008) estudou as concepções de universidade dos intelectuais paranaenses entre 1892 e 1950. Os documentos que servem de substrato a sua análise acerca da FFCLPR reproduzem as falas de seus diretores e principais catedráticos, compreendendo textos publicados na Revista do CEB, nos Anuários da Faculdade, em um volume apropriadamente chamado de "Diretrizes à juventude" (que contém discursos de paraninfos ligados a essa rede) e na Revista A Cruzada, veículo da imprensa católica no Paraná. A leitura dessas fontes deixa clara a presença das ideias tomistas nos discursos desses intelectuais: "o grupo católico (...) questionava a postura dos cientistas quando se propunham a fazer ciência e não se ocupavam de discutir as questões filosóficas que estavam presentes nas suas metodologias científicas. (...) A metafísica católica implicava na compreensão de Deus por meio da razão, pois ela explicava a relação entre a natureza, as coisas, os seres humanos e a Substância, ou seja, Deus. Era uma relação entre o efeito e a causa primeira” (Campos 2008: 160). Um elemento fundamental deste ideário está ligado ao fato de que a produção científica não era negada para a afirmação da religião: "à ciência cabia pesquisar e trazer o progresso material à vida humana. Nesses termos, o saber científico era fundamental, entretanto ele não consistia em um fim em 
si mesmo, pois os fins eram os princípios universais estabelecidos pela metafísica católica" (op cit: 162, 163). Deste modo, segundo Campos, os catedráticos da Faculdade ligados ao CEB não propunham um ensino religioso, mas sim um ensino da ciência enquanto meio de acesso a um conhecimento mais verdadeiro, pois que ligado às obras de Deus: "o laicato católico paranaense não defendia a presença do conhecimento teológico como disciplina na UP, entretanto afirmava uma concepção deísta da natureza e da história” (op cit: 216).

Assim, tudo pareceria indicar que a FFCLPR, dirigida já a partir de seu segundo ano de existência por membros da rede de intelectuais paranaenses ligados ao catolicismo, teria se estabelecido como uma das instituições responsáveis pela disseminação do projeto cultural e político da Igreja Católica para o Brasil. Mas devemos ter em mente que as fontes levantadas por Campos - assim como o discurso aos bacharéis de Loureiro Fernandes citado acima - não nos informam sobre o significado efetivamente assumido pela FFCLPR; eles nos informam, antes, sobre as intenções programáticas desses intelectuais para a Faculdade. São elocuções destinadas a marcar a posição oficial da instituição em ocasiões públicas. Há uma diferença fundamental, assim, entre as falas programáticas que constam das fontes trabalhadas por Campos, as atitudes efetivas enquanto docentes e intelectuais públicos dos catedráticos que as enunciaram e os resultados efetivos desse programa na vida da Faculdade - ou seja, entre as concepções de universidade, que são o foco da atenção da pesquisa de Campos, e as dinâmicas efetivamente levadas a cabo no cotidiano da FFCLPR. Nas palavras de Miceli (1989a: 11), "da perspectiva dos efeitos encadeados sobre a vida social, política e intelectual, o valor de qualquer plataforma de ideias somente pode ser devidamente aquilatado em função da realidade institucional instaurada, das práticas a que deu origem, dos profissionais nela engajados".

Por outro lado, isso não significa que a compreensão dessa plataforma em si não aporte conhecimento algum acerca das dinâmicas concretas que ali ocorreram, pois a partir dela os agentes definiram a si próprios e aos embates institucionais em que se envolveram. No presente artigo, o que buscamos tematizar são algumas das práticas intelectuais e políticas de Loureiro Fernandes, um dos catedráticos ligados a essa rede de intelectuais. E, para isso, temos que compreender qual o sentido que ele atribuiu a esse projeto institucional e como agiu com base em suas interpretações dele.

Ao abrir um diálogo com as ciências modernas, o neotomismo colocou seus seguidores em contato íntimo com a multiplicidade dos saberes científicos contemporâneos: se este projeto tinha por finalidade última a restauração da centralidade da filosofia católica no mundo moderno, o motor desta transformação era o próprio conhecimento científico. Em termos programáticos, como vimos, esse contato com a ciência deveria ser submetido à crítica ao "cientismo", ou seja, as verdades da ciência deveriam ser submetidas às Verdades metafísicas últimas da religião. Contudo, nas práticas científicas efetivas dos intelectuais da FFCLPR ligados a essa rede, o limite até onde se estendia a verdade científica e a partir de onde se estabelecia a Verdade do dogma variava. Abordemos então como Loureiro se colocou frente a essa questão. 


\section{O debate}

A atração irresistível exercida pelo mistério sobre o espírito humano faz arrojados e talentosos romancistas se aventurarem no campo da ciência, em busca de temas para um êxito de livraria. (...) a imaginação poderosa dos novelistas [é] capaz de despertar no vulgo, a par de ideias disparatadas, o interesse pelos complexos problemas científicos. O que é de lamentar é que a imaginação romântica embriague também, às vezes, os homens de ciência, e que, em vez da análise fria dos fatos observados, encontremos também sob autoria de suas penas, hipóteses ardentemente apaixonadas. (...) Encarando o tema da antiguidade do homem com toda a honestidade científica somos forçados a pôr à margem todas as ossadas humanas fósseis que não apresentem características definidas, comprobatórias de sua autenticidade. São características essenciais que abonam o valor destas peças ósseas pré-históricas: a fossilização, isto é, 'a transformação física e clínica dos ossos pela perda de matéria orgânica e enriquecimento em matérias minerais'. Como consequência sobrevém o aumento da densidade, adquire o osso um peso muito maior. Mas este caracter não basta, pois o grau de fossilização pode variar com as condições do meio, independente do tempo decorrido. (...) À colaboração de geólogos competentes devem os paleontologistas a solução de interessantes problemas. (...) Finalmente, o estudo das manifestações rudimentares da atividade humana (Arqueologia Pré-Histórica) também traz um raio de luz nas sombras misteriosas deste longínquo passado. Apressemo-nos em dizer que, mesmo em posse de todos estes característicos só podemos, no estado atual da ciência, dar uma ideia aproximada sobre a antiguidade do homem.

(...) Como vemos, a cronologia pré-histórica dá seus primeiros passos, mas não deixa por isso de ser interessante. Tivemos a esse respeito uma curiosa contribuição de um dos mais ilustrados membros do CEB, fixando pelo cálculo matemático em 2 [milênios] a antiguidade do homem. (...) [recair em tal definição] seria copiar os homens de ciência de outrora, que se deixavam arrastar pela caudal dos números e faziam pura fantasia científica. $\mathrm{O}$ momento das afirmações categóricas ainda não chegou. ${ }^{8}$

Em meio a inúmeras citações do estado da arte nas pesquisas da Paleontologia, da Geologia e da Arqueologia de sua época, foi com estes argumentos que Loureiro Fernandes, na sessão de 3 de julho de 1930 do CEB, refutou a fala proferida pelo "bandeirante" Waldemiro Teixeira de Freitas três semanas antes. O tema de Teixeira de Freitas tinha sido "A antiguidade da linhagem humana à luz da Matemática”. Em sua elocução," este professor da Faculdade de Engenharia do Paraná buscou demonstrar como "os dados estatísticos do aumento proporcional da população do orbe terráqueo e dos índices gradativos de cada país (...) assegura o cálculo global de uma constante proporcional gradativa que daria para o aparecimento do primeiro casal saído das mão do Criador de todas as coisas um período equivalente de 2000 anos aproximados", configurando sua fala como uma tese "em apoio da gênese bíblica”. A fala de Teixeira de Freitas não foi contestada de imediato, mas sim pela lectio de Loureiro Fernandes; segundo a ata dessa sessão, ${ }^{10}$ após o intervalo para a meditatio, padre Miele declarou "constar do expediente" uma quaestio, deixada na caixa de consultas do CEB. A questão colocada foi: "que se

\footnotetext{
8 Arquivo do Círculo de Estudos Bandeirantes, DOC2322.

9 Registrada no LIVRO DE ATAS DO CEB, vol. I, pp. 58v-59.

10 Registrada no LIVRO DE ATAS DO CEB, vol. I, pp. 67-68.
} 
deve pensar a respeito da discordância entre os dados da Bíblia e as conclusões da ciência no campo da pré-história?”. A resposta imediata de Miele foi que “nenhum conflito poderia existir entre as verdades da fé e as verdades da ciência. (...) uns são os caminhos determinados por Deus e outros são os delineados pelo homem em demanda da verdade, que é o próprio Deus - um é o caminho reto da Verdade, outro o caminho sinuoso da dúvida e das hipóteses acerca da verdade". Miele abriu a seguir espaço para as disputationes, mas ninguém quis se manifestar. Meses depois, na sessão de 2 de outubro de 1930, ${ }^{11}$ Miele declarou que considerava seu dever aprofundar sua resposta anterior à consulta sobre "o conflito entre as legítimas conclusões da ciência e as autênticas assunções da Bíblia”. Miele sublinhou que não poderia haver duas verdades, pois “a verdadeira ciência nasce da razão humana iluminada por Deus": a verdade científica de hoje era o erro de amanhã; os sábios de ciência que só confiavam nas conclusões de deduções soberanas se enganavam; a Verdade primeira e suma, única e integral era Deus, e a ciência desapareceria quando essa Verdade se revelasse.

Esses materiais nos dão acesso às dinâmicas concretas que ocorriam no âmbito das reuniões da rede de intelectuais paranaenses no CEB. Vemos como este era um espaço de embates, no qual cada membro tinha sua própria compreensão acerca dos limites entre ciência e religião, e no qual essas compreensões eram colocadas em confronto. Ele nos informa também sobre a postura de Loureiro Fernandes a esse respeito nesses primeiros anos de funcionamento da instituição. Ele já tinha antes sido o responsável pela lectio de 30 de janeiro de 1929, na qual falou sobre a Histeria. Nessa ocasião, referiu-se aos processos da Inquisição, que se referiam a "pactos anormais e estranhos, desconhecidos ou mal interpretados pela velha patologia, e hoje elucidados pela luz da moderna ciência médica”. Segundo a ata da sessão, Loureiro "expôs interessantes casos de diabolismo, epilepsia, sonambulismo, obsessões e catalepsias que se radicavam inteiramente à neurose histérica dos vitimados" ${ }^{12}$ Tendo concluído sua tese em Medicina em 1927, e passado a seguir um ano se especializando em Urologia clínica em um hospital especializado de Paris, Loureiro chegava a Curitiba convicto do valor do saber científico, e confrontando-o às ideias católicas no âmbito do próprio CEB.

Nos anos que se seguiram, Loureiro passou a ter um contato aprofundado com as discussões dirigidas pelo viés neoescolástico de Miele, e seguiu a formação filosófica proposta por Ballarin - o que, como vimos no item anterior, deixou fortes marcas em seu pensamento. Mas ele se aproximou da proposta tomista vindo de uma formação científica intensiva, e isso deixaria marcas no modo pelo qual ele buscaria conciliar sua formação filosófica e sua formação científica.

Sua carreira como cientista e como institucionalizador de espaços científicos foi longa e multifacetada, e teremos aqui espaço apenas para indicar alguns elementos de sua atuação nesses campos. A partir de 1936, ele reestruturou o Museu Paranaense, criando nele seções especializadas em Zoologia, Botânica, Geologia, e congregando ali um corpo científico composto por especialistas que já tinham ou viriam a ter destaque em suas respectivas áreas, e coordenando a publicação da revista científica Arquivos do Museu Paranaense, que viria a ter circulação internacional. Quando dificuldades políticas colocaram em risco a manutenção da estrutura do Museu Paranaense, Loureiro articulou a criação

11 Registrada no LIVRO DE ATAS DO CEB, vol. I, pp. 97-97v.

12 Registrada no LIVRO DE ATAS DO CEB, vol. I, p. 25 v. 
do Instituto de Pesquisas da recém-federalizada Universidade Federal do Paraná para ali alocar seus cientistas do Museu. ${ }^{13}$ Em paralelo a esse trabalho pela institucionalização de espaços de produção de ciência, Loureiro Fernandes dedicou-se a estudos de uma Antropologia Física de caráter evolucionista, realizando pesquisas sobre a hematologia de populações indígenas e sobre a Antropologia das Técnicas entre a população do litoral paranaense e os índios Xetá. Seu envolvimento com a Antropologia colocou-o em contato próximo com os pesquisadores envolvidos na institucionalização da área no Brasil, e ele assim aparece entre os membros fundadores da Associação Brasileira de Antropologia, tendo sido seu presidente entre 1957 e 1959. Por fim, no início dos anos 1950, após um ano de estudos de especialização no Musée de L 'Homme de Paris junto a Paul Rivet e Leroi Gourhan, Loureiro romperia publicamente o vínculo que havia constituído com os pesquisadores envolvidos nos estudos de folclore no Brasil, afirmando que os fenômenos abordados por essa área apenas poderiam ser abordados cientificamente a partir da Antropologia. ${ }^{14}$

Podemos ter mais clareza acerca da posição de Loureiro frente aos limites entre ciência e religião ao comparar sua postura com a de dois outros importantes catedráticos da FFCLPR ligados a essa rede de intelectuais católicos. O primeiro deles é Bento Munhoz da Rocha Netto. Nas palavras de Hanicz (2006: 259, 260), “entre os católicos do Paraná, [ele] talvez tenha sido o que mais absorveu o pensamento de Tomás de Aquino (...). As ideias de Bento Munhoz, sobretudo no que tange à verdade, sugerem uma certa universalidade do pensamento tomista, apontam para algo que está para além das fronteiras do mundo católico e da própria fé católica”. Ao lecionar Sociologia como catedrático da FFCLPR entre 1940 e 1946, Bento Munhoz utilizou como referência a ideia de uma Sociologia Integral proposta por Alceu Amoroso Lima. Nessa concepção, a sociologia moderna aparecia como limitada, por considerar apenas uma parte do conhecimento sociológico possível: ela observaria apenas os processos fenomênicos da realidade, desconsiderando seus aspectos metafísicos (Meucci 2000: 69, 70). A pesquisa de Patrícia Prado (2017: 86) cita o depoimento de um de seus ex-alunos, Alberto Woiski, segundo quem "a disciplina conduzida por Bento Munhoz era profundamente humanista, pois explicava o homem como construtor da sociedade, ao contrário das teorias materialistas e comunistas que, a seu ver, subsumiam o homem à vida social”. Nas palavras de Woiski, “o prof. Bento nos colocou dentro da sociologia cristã. Só havia um livro na linha dessa doutrina, o de Alceu Amoroso Lima - Tristão de Athaíde. Esse livro foi analisado de ponta a ponta" (id, ibid). No caso de Bento Munhoz, assim, a própria metodologia científica estava intrinsecamente ligada à filosofia católica.

Já as elocuções de Brasil Pinheiro Machado - catedrático de História da FFCLPR - que foram registradas nos primeiros anos de existência da instituição indicam que, para ele, questões metodológicas deveriam ser discutidas a partir dos avanços da própria disciplina histórica. Em tese recente que revisa o sentido da produção historiográfica e das ações de Pinheiro Machado como jurista e como político, Marchette (2017) demonstra como ele construiu uma "visão particular e moderna sobre a

13 Participaram do corpo científico do Museu paranaense, por exemplo, o entomólogo Jesus Moure, o naturalista e etnógrafo Günther Tessmann, o taxidermista Andreas Mayer e o geólogo Reinhardt Maack. A respeito do Museu Paranaense e da atuação de Loureiro Fernandes em sua direção, ver Ardigó (2011).

14 Esse episódio é citado por Vilhena (1997: 142, 143). O envolvimento de Loureiro Fernandes com a área de estudos de folclore está sendo estudado por Gustavo Macedo, que está em fase de conclusão de sua dissertação a respeito do assunto no PPGA da UFPR. 
história", em que "o positivismo (...) era superado pela influência dos avanços na pesquisa documental e da moderna historiografia de viés cultural" (op cit: 68). Convidado para ministrar a aula inaugural do ano letivo de 1940 da Faculdade, Pinheiro Machado não abordou em momento algum o projeto tomista ou a centralidade última do pensamento religioso. Na ocasião, ao contrário, destacou que "a nova 'massa documentária' à disposição dos estudiosos da história daria condições da ultrapassagem de velhas perspectivas, com a superação do viés político pelo cultural, bem como a imposição de revisões constantes nas conclusões, mais do que nunca de caráter temporário” (op cit: 91).

No entanto, ao mesmo tempo em que suas reflexões metodológicas se afastavam do discurso tomista, suas teses centrais mantinham um forte vínculo com um olhar conservador de caráter religioso. Um dos temas centrais de seu pensamento e de sua atividade política dizia respeito ao papel ativo que as instituições de saber deviam desempenhar na definição dos rumos futuros da nação. Em uma fala registrada em um evento do mesmo ano de 1940, Pinheiro Machado afirmava que "o elemento capaz de garantir o rumo deveria ser a cultura ordenada de acordo com sua 'unidade e tradição', isto é, com adaptações aos diferentes momentos históricos sem, no entanto, causar mudanças na sua essência, na sua identidade" (op cit: 164). A busca pela identidade nacional deveria assim atentar à tradição formadora da nacionalidade brasileira - e essa podia ser encontrada na tradição cristã. Assim, a historiografia de Machado

fez uma conexão direta entre a tradição cristã e a conquista da autonomia cultural do país; a consolidação da autonomia [estava ligada à] manutenção dessas origens e [era] a garantia da unidade cultural e política do Brasil. A história, portanto, enquanto método, tinha a função técnica de instrumentalizar e disciplinar as transformações dessas origens, no tempo. Os espaços mais adequados para aplicar essa técnica eram as faculdades de filosofia espalhadas pelo país e lideradas pelo espírito da harmonia cristã (op cit: 168).

Loureiro Fernandes assumiu uma posição diversa em relação àquelas que observamos nas atuações de Bento Munhoz e Pinheiro Machado. Assim como no caso desses dois intelectuais, a religião é um tema frequente em vários de seus textos do período que se estende até os anos 1950; mas ela assume aí um outro estatuto, funcionando apenas como uma caução última para a ciência que ele praticava - como um limite filosófico para o "cientismo". A essência de seu trabalho era voltada à produção propriamente científica - uma produção marcada por um viés fortemente evolucionista.

O que as diferenças entre as posições de Bento Munhoz, Pinheiro Machado e Loureiro Fernandes parece nos indicar é que, por um lado, o projeto inscrito na encíclica de Leão XIII - intermediado pelas discussões coordenadas pelos padres Miele e Ballarin no CEB e discutido a partir da leitura das obras de intelectuais católicos como Alceu Amoroso Lima - estabeleceu efetivamente os parâmetros que mobilizaram os embates em que se envolveram os catedráticos católicos que participavam da FFCLPR. Por outro lado, fica claro que isso não se traduziu na constituição de um "grupo católico" homogêneo, nem de um conjunto de "militantes católicos" que operasse como um grupo internamente 
coerente. ${ }^{15}$ Se o CEB e a FFCLPR haviam efetivamente congregado agentes ao redor de um projeto intelectual neotomista, as falas programáticas e os discursos oficiais de seus intelectuais e dirigentes constituem fontes que, analisadas em seu valor de face, podem levar a conclusões equivocadas.

Assim, a "unidade e a coesão" que Westphalen considerava que haviam sido rompidas ao longo dos "anos tumultuados" da FFCLPR são princípios equivocados para a análise, pois os membros dessa rede de intelectuais enfeixavam desde seu início compreensões divergentes acerca dos objetivos desse projeto. Essas diferenças apenas cresceram ao longo do tempo, resultando, a partir da questão da concessão de títulos de livre docência, em uma polarização aparentemente assentada em duas posições opostas. ${ }^{16}$ Mesmo dentro dessas posições opostas não havia "unidade" ou "coesão" - visto que tomaram posição ao mesmo tempo contra o diretor Homero de Barros intelectuais externos à rede dos católicos, como Wilson Martins, e intelectuais ligados ao CEB. ${ }^{17} \mathrm{E}$ mesmo dentre esses últimos, como vimos, existiam projetos políticos e de conhecimento distintos entre si.

O caso de Loureiro Fernandes é especialmente interessante. Pois o que indica a carta que ele dirigiu ao padre Luigi Castagnola, com que iniciamos o presente artigo, é que a questão relativa aos limites entre a Verdade do dogma e as verdades da ciência não gerou discórdia apenas entre os diferentes membros ligados a essa rede de intelectuais envolvidos com a proposta neotomista. O próprio Loureiro, muitas vezes descrito na literatura a seu respeito simplesmente como um "intelectual católico" ou um "militante católico", surge em sua carta internamente dividido por essa questão. Educado por família religiosa, formado na ciência a partir de suas leituras e pesquisas na Medicina, na Antropologia e nas áreas correlatas pelas quais se interessou, marcado a ferro e fogo por sua formação filosófico-religiosa e por sua formação científica, Loureiro parece concentrar em sua trajetória pessoal e intelectual as contradições do programa de Leão XIII. O que ocorria na FFCLPR e na trajetória de Loureiro era parte integrante do desenrolar do projeto da Igreja Católica romana: essas dinâmicas sociais aparentemente locais ultrapassavam em muito os limites geográficos em que os eventos aqui enfocados ocorreram, estando ligadas a eventos e projetos mais amplos. Como afirma Revel (1992:28),

cada ator histórico participa, de maneira próxima ou distante, de processos - e portanto se inscreve em contextos de dimensões e de níveis variáveis, do mais local ao mais global. Não existe portanto hiato, menos ainda oposição, entre história local e história global. O que a experiência de um indivíduo, de um grupo, de um espaço permite perceber é uma modulação particular da história global. Particular e original, pois o que um ponto de vista micro-histórico oferece à obser-

15 Evidentemente, isso não significa que tais "militantes" não existissem, o que já fica claro a partir da alusão que Loureiro faz à carta recebida de Castagnola. Ao restringirmos nossa análise a esses três catedráticos, assim, não pretendemos esgotar a análise das posições possíveis nesses embates. Se enfocássemos aqui o próprio diretor Homero de Barros, por exemplo, veríamos um catedrático com um perfil menos acadêmico e mais engajado na luta política da Igreja. Para algumas indicações a esse respeito, ver Machado, 2006.

16 No trecho que segue, a própria professora Westphalen reconhece seu incômodo com a leitura dualista que ela mesma constrói a respeito: "A questão, na verdade, consistia na luta pelo poder entre dois grupos desejosos da direção e da orientação da Faculdade, separados por ideologias conflitantes, os católicos-clericais e os liberais anti-clericais, ainda que essa classificação comportasse diferentes nuanças (Westphalen op cit: 40, grifos adicionados).

$17 \mathrm{O}$ documento enviado ao reitor da UFPR questionando a recondução de Homero de Barros à direção da FFCLPR indica que entre os catedráticos que tomaram posição contra ele estavam Wilson Martins, Temístocles Linhares, Osvaldo Pilotto e os membros do CEB Jesus Moure, Homero Braga, Liguaru Espirito Santo, Bento Munhoz da Rocha Neto e Brasil Pinheiro Machado (Machado op cit: 28, 40). 
vação não é uma versão atenuada, ou parcial, ou mutilada de realidades macrossociais; é (...) uma versão diferente.

Nesse sentido, não devemos depreender que Loureiro seja um representante "típico" ou "ideal" de um "grupo católico", ou que a FFCLPR tenha operado de fato seguindo as diretrizes programáticas da Igreja. ${ }^{18} \mathrm{E}$ é apenas por uma leitura atenta das fontes de que vimos tratando neste artigo que poderemos compreender de fato a situação humana vivida por esses intelectuais.

\section{O discurso do cidadão honorário}

De todas as distinções honoríficas que recebi, nenhuma tão alta em significação como esta para minha vida de brasileiro (...). Nestas buscas das razões íntimas que me haviam trazido a convicção de ser um cidadão de Curitiba (...) invoquei e foram preponderantes as tradicionais raízes de família que por gerações me vinculam ao passado desta cidade. São os vínculos maternos, em cuja ascendência patrilinear há, novamente, um avô beirão - José Fernandes Loureiro, brasileiro por naturalização, presidente que foi desta Câmara, intendente municipal, governou a cidade (...). A linha matrilinear desta progênie vive em cinco gerações da história de Curitiba, através do tronco Corrêa de Bittencourt, aqui radicado há dois séculos. (...) Destas figuras do passado , evocações familiares recordam-me nos idos coloniais um oficial de milícias, José Corrêa Bittencourt, e nos tempos da Província do Paraná o Coronel Manoel José da Cunha Bittencourt, senhor abastado, a estimular nestas paragens a incipiente indústria da erva-mate. (...) Para timbre bem brasileiro de nossa genealogia, não nos faltou (...) nem o vulto respeitável de um sacerdote, representado pelo meu venerando tio avô - Padre Júlio Ribeiro de Campos, primeiro vigário geral da paróquia de Nossa Senhora da Luz dos Pinhais de Curitiba. (...) neste momento, quando as neves do inverno da vida começam a pontilhar minhas têmporas, devo começar a rememorar aos descendentes meus [essas tradições], acrescida da progênie de minha dedicada esposa do tronco ilustre dos Lustozas de Andrade. ${ }^{19}$

José Loureiro Fernandes escolheu agradecer a concessão do título de cidadão honorário de Curitiba, a ele outorgado pela Câmara Municipal em janeiro de 1960, marcando sua longa vinculação genealógica com as famílias da elite local. Seu avô, José Fernandes Loureiro, foi peça chave desta genealogia, pois, vindo de outro país, foi quem criou vínculos e relações de aliança com a elite local. Imigrante português, enriqueceu a partir de suas atividades no comércio; ainda jovem, casou com a neta de um industrial da erva mate, de família tradicional curitibana. A partir dos laços estreitos que construiu com Ildefonso Pereira Correia, o barão do Serro Azul, maior empresário paranaense de sua época, foi membro fundador da Associação Comercial do Paraná e fundador do Clube Curitibano, associação recreativa e cultural que congregava a elite local. Foi também membro fundador e provedor da Irmandade da Santa Casa de Misericórdia; fazia parte da Irmandade da Nossa Senhora da Luz dos Pinhais, foi fundador da Sociedade Portuguesa Beneficente Primeiro de Dezembro e membro das lojas

18 O discurso feito por Alceu Amoroso Lima aos bacharéis da instituição quando nela esteve como paraninfo da turma de 1943 deixa explícito como essas elocuçôes constituíam falas performáticas que visavam a um objetivo político: "nesta Faculdade, graças a Deus, não impera o ecletismo e sim a hierarquia dos valores. E o Sinal da Cruz não é neste recinto um simples símbolo optativo, e sim a própria marca da Verdade" (in Anuário da Faculdade de Filosofia, Ciências e Letras do Paraná de 1943, p. 61).

19 Arquivo do Círculo de Estudos Bandeirantes, DOC2253. 
maçônicas Apostolo da Caridade e Fraternidade Paranaense. Ao falecer, deixou enorme patrimônio composto de imóveis e investimentos financeiros, incluindo um saldo mensal de três contos de réis a ser retirado da conta corrente de sua sociedade comercial, destinada perpetuamente a seus netos (Cardoso 2011: 45 a 48).

O envolvimento de imigrantes portugueses com obras de caridade e irmandades religiosas confirmava seu status enquanto participantes da elite local (Boxer 2002: 302); e, como vimos, se a participação nas Irmandades era característica da religiosidade portuguesa no Brasil durante o período imperial, na época da juventude de Loureiro Fernandes essa atividade tinha se deslocado para a esfera da intelectualidade. ${ }^{20}$ Assim, tanto ele quanto seu avô atenderam às expectativas sociais relativas à posição que ocupavam: ao aceitar organizar e participar de instituições culturais laicas católicas a partir das demandas de religiosos como padre Miele, Loureiro Fernandes atendia a um mandato social, cujo cumprimento era esperado por todos.

Mas isso não significou que ele cumpria essa missão cegamente: munido de uma constante vigilância crítica, ele - assim como Bento Munhoz e Pinheiro Machado - definiu sua própria compreensão acerca do projeto tomista que lhe foi imputado. Ao invés de, em nossa análise, buscar nas falas desses intelectuais indicativos de sua posição na estrutura social, de supostos interesses ou de estratégias de classe a serem desvendadas pelo analista, optamos por atentar às justificativas que eles mesmos emprestavam a seus atos, com o objetivo de compreender o sentido que eles próprios atribuíam a suas ações - e, assim, de entendê-las, e de entendê-los enquanto sujeitos ativos. Daí a atenção emprestada, neste artigo, às falas, às ações e às justificativas de Loureiro Fernandes, de cuja trajetória tomamos alguns elementos como eixo de argumentação para falar dos agentes ligados a essa rede.

Pelo mesmo motivo, evitamos agregar os intelectuais aqui enfocados sob denominações como "grupo católico", "meio católico", "grupo clerical” ou expressões similares. Certamente todos constituíam uma rede de pessoas ligadas e interdependentes; no caso dos agentes aqui abordados, todos eram membros de uma fração bastante seleta da elite curitibana. Eles foram "herdeiros" que poderiam ter se restringido a ocupar as posições dirigentes que já lhe estavam destinadas, mas decidiram seguir carreiras intelectuais, mesmo que, em certos casos, apenas durante um determinado período ou em paralelo a carreiras profissionais ou políticas. ${ }^{21}$ Mas as diretrizes que de fato seguiram em suas ações, como

20 O que não significa que as Irmandades tenham se extinguido. O próprio Loureiro Fernandes ocupou também, como seu avô, a posição de provedor da Santa Casa de Misericórdia. Para informações a respeito de sua compreensão acerca das Irmandades, é possível consultar uma palestra que ele fez a respeito no arquivo do CEB (DOC382).

21 Muitos de fato o fizeram: Bento Munhoz foi deputado federal e governador do Estado, e talvez tenha sido um dos que menos efetivamente participou da Faculdade após 1946, quando assumiu seu mandato; Pinheiro Machado foi prefeito da cidade de Ponta Grossa, deputado estadual, interventor federal no Paraná e procurador-geral da justiça ao final do regime Vargas, mas manteve-se sempre ativo em sua vida de pesquisador; já Loureiro Fernandes, apesar de ter sido convidado várias vezes a seguir carreira política e a assumir cargos de relevância, aceitou apenas o de Secretário de Educação e o cumprimento de um mandato de vereador, afirmando sempre que apenas aceitaria funções políticas que estivessem relacionadas com suas atividades como professor e pesquisador. Dentre os intelectuais paranaenses desse período, poderíamos citar ainda, por exemplo, o catedrático de Ciência Política da FFCLPR Manoel de Lacerda Pinto, que foi deputado federal, desembargador, procurador geral do Estado e presidente do TRE-PR; e David Carneiro, grande industrial da erva mate, autor de ampla obra historiográfica, que não chegou a se envolver com a Faculdade (a seu respeito, ver por exemplo Doberstein 2017). Sobre esse assunto, é importante destacar que enxergar as produções desses intelectuais de fora do eixo Rio-São-Paulo apenas a partir de suas "limitações" em relação aos parâmetros atuais dos cânones científicos nos afasta da compreensão de suas produções intelectuais em seus próprios termos. Como afirmam autores que se dedicaram a estudar a institucionalização das Ciências Sociais em diferentes estados, um olhar que parte dos critérios atuais de ciência redunda em um empobrecimento das perspectivas de análise acerca desses agentes (ver a respeito, por exemplo, Trindade 2004: 145 a 148, Vilhena 1997: 52 a 54 e Oliveira 2006: 13). 
vimos, eram diversas entre si. E seus motivos para dedicar-se à atividade intelectual apenas podem ser compreendidos se perscrutarmos suas atitudes e seus escritos, e os confrontarmos com as justificações que eles apresentam para terem seguido esse caminho.

Assim, ao nos aproximarmos das reflexões pessoais de Loureiro Fernandes e de seus pares, podemos compreender o ambiente social da FFCLPR de um modo diferenciado, tendo acesso às brechas e contradições dos sistemas normativos aos quais ele esteve vinculado, e às "ambiguidades do mundo simbólico, à pluralidade das possíveis interpretações desse mundo e à luta que ocorre em torno dos recursos simbólicos e também dos recursos materiais" (Levi 1992: 136). Essa linha de análise torna possível perscrutar o ambiente intelectual da FFCLPR a partir de pontos de vista distintos, abrindo para o futuro novas perspectivas de análise sobre esse mundo social. Hoje temos acesso, por exemplo, a vários depoimentos memorialísticos de ex-alunos e ex-professores da instituição, em grande parte registrados nas efemérides comemorativas do Setor de Ciências Humanas da UFPR, que herdou boa parte dos quadros da FFCLPR. ${ }^{22}$ Diversas pesquisas acerca de personagens de destaque dessa história têm sido realizadas - e já pudemos aqui nos beneficiar de algumas delas. A partir desses materiais, a opção por uma "análise microscópica e um estudo intensivo do material documental", como propõe Levi ( $o p$ cit: 136), permite o levantamento de novas leituras e hipóteses, "revelando fatores previamente não observados": "fenômenos previamente considerados como bastante descritos e compreendidos assumem significados completamente novos quando se altera a escala de observação" (op cit: 139, 141).

Ao diminuir a escala de nossas pesquisas, assim, aproximamos nossas análises da complexidade dos mundos sociais vividos pelos diferentes agentes que enfocamos em nossas pesquisas. A partir desses esforços, pudemos aqui produzir uma leitura mais nuançada acerca do universo social da FFCLPR. E, como vimos, as redes dos intelectuais a elas ligados estavam entrelaçadas com as de outras Faculdades e instituições culturais e religiosas como a USP e o Centro Dom Vital. Ao seguir as dinâmicas dessas redes, assim, logramos entender de um modo mais profundo a genealogia sócio-histórica das instituições culturais e das universidades brasileiras em geral.

\section{Paulo Guérios é mestre e doutor em Antropologia pelo PPGAS/Museu Nacional e professor do Departamento de Antropologia e do PPGA da UFPR.}

\footnotetext{
22 É interessante destacar que nenhum desses depoimentos constrói uma imagem de uma instituição de caráter religioso. Desse modo, efetivamente, o projeto defendido pelos intelectuais ligados à rede católica mais aguerridos, como Homero de Barros, não parece ter vingado, dado que os discentes formados nos quadros da FFCLPR não seguiram as "diretrizes à juventude" por eles definidas. Seria interessante, se houvesse espaço, comparar mais detidamente a divergência entre o projeto original e os processos sociais efetivos que se desenrolaram na FFCLPR e na Faculdade de Filosofia da USP - com certeza mais estudada. Florestan Fernandes (1977: 216 a 230), por exemplo, destaca como o projeto da oligarquia e da burguesia paulista para a FFCL da USP visava à retomada do controle e da hegemonia perdidas na década de 1930 a partir da formação de quadros intelectuais para as elites das classes dominantes. Contudo, esses fundadores não se dedicaram à Universidade, acreditando que a excelência técnica dos professores estrangeiros contratados por eles redundaria automaticamente nos resultados por eles esperados. Florestan destaca como ele e seus colegas, ao contrário, buscaram desenvolver a partir da formação recebida desses professores uma leitura própria do mundo social. No Paraná, a própria elite assumiu as cátedras. Como vimos na nota anterior, o grau de comprometimento efetivo com as tarefas acadêmicas variou muito entre esses catedráticos ainda não vinculados a um regime de dedicação exclusiva ao ensino e à pesquisa. Mas mesmo com o engajamento integral de alguns deles, o projeto não vingou, demonstrando por um lado as divergências na compreensão deste projeto, como demonstramos ao longo do artigo, e por outro lado o caráter incontrolável dos processos sociais.
} 


\section{REFERÊNCIAS BIBLIOGRÁFICAS}

ARDIGÓ, F. 2011. “Uma ciência improvável: o Museu Paranaense entre 1940 e 1960”. In:

(org.), Histórias de uma ciência regional: cientistas e suas instituiçôes no Paraná (1940-1960). São Paulo: Contexto, pp. 101-176.

BOXER, C. 2002. O império maritimo português 1415-1825. São Paulo: Companhia das Letras.

CAMPOS, N. 2008. Intelectuais paranaenses e as concepções de universidade (1892-1950). Curitiba: Editora da UFPR.

CARDOSO, M. 2011. José Fernandes Loureiro: um imigrante português em Curitiba (1860-1908). Trabalho de conclusão de curso em História. Curitiba: UFPR.

FERNANDES, F. 1977. “A geração perdida”. In: . A sociologia no Brasil. Petrópolis: Vozes, pp. 213-252.

FERRARINI, S. 2011. Circulo de Estudos Bandeirantes documentado. Curitiba: Editora Champagnat.

FURTADO, M. R. 2000. "O Círculo de Estudos Bandeirantes e a formação acadêmica no Paraná”. Revista do Círculo de Estudos Bandeirantes, 14, pp. 113-128.

GLASER, N. 1988. "Educação na história da UFPR: apontamentos para uma minuta cronológica”. Educar, Curitiba, 7 (1/2), pp. 13-58.

HAINSWORTH, P. e Robey, D. (eds.) 2005. The Oxford companion to Italian Literature. Oxford: Oxford Un. Press.

HANICZ, T. 2006. Modernidade, religião e cultura. O Círculo de Estudos Bandeirantes e a restauração do catolicismo em Curitiba (1929-1959). Tese de doutoramento em Ciências da religião. São Paulo: PUC.

LEVI, G. 1992. “Sobre a micro-história”. In: Burke, P. (org.), A escrita da história: novas perspectivas. São Paulo: Editora da UNESP.

MACHADO, V. 2006. "Homero Batista de Barros: uma odisseia contra o comunismo". Anais do XV Encontro Regional de História. Curitiba: DEHIS / UFPR. .2009. Diatribes viperinas e digressões quixotescas: debates intelectuais e projetos educacionais na década de 1950. Tese de doutoramento em Sociologia. Curitiba: UFPR.

MARCHETTE, T. 2017. A trajetória de Brasil Pinheiro Machado e a construção da historiografia regional do Paraná no território acadêmico;1928-1953: do poema ao modelo historiográfico. Tese de doutoramento em história. Curitiba: UFPR. 
MEUCCI, S. 2000. A institucionalização da Sociologia no Brasil, os primeiros manuais e cursos. Dissertação de mestrado em Sociologia. Campinas: UNICAMP.

MICELI, S. 1985. A elite eclesiástica brasileira (1890-1930). Tese de livre-docência em Sociologia. Campinas: Unicamp.

1989a. "Por uma sociologia das ciências sociais". In: (org.), História das ciências sociais no Brasil, vol.1. São Paulo: Instituto de Estudos Econômicos, Sociais e Políticos de São Paulo (IDESP), pp. 5-19.

1989b. "Condicionantes do desenvolvimento das Ciências Sociais no Brasil (1930-1964)". In: . (org.), História das ciências sociais no Brasil, vol.1. São Paulo: Instituto de Estudos Econômicos, Sociais e Políticos de São Paulo (IDESP), pp. 72-110.

OLIVEIRA, M. 2006. “Sociologia das Ciências Sociais no Paraná”. In: . (org.), As Ciências Sociais no Paraná. Curitiba: Contexto, pp. 9-33.

PRADO, P. 2017. De autodidatas a cientistas: a institucionalização do curso de Ciências Sociais da Faculdade de Filosofia, Ciências e Letras do Paraná, 1938-1960. Trabalho de conclusão de curso em Ciências Sociais. UFPR: Curitiba.

REVEL, J. 1992. “Microanálise e construção do social”. In: . (org.). Jogos de escalas. A experiência da microanálise. Rio de Janeiro: Janeiro: Ed. da FGV, pp. 15-38.

ROUWENDAL, P. L. 2010. "The Method of the Schools: Medieval Scholasticism". In: van Asselt, W. Introduction to Reformed Scholasticism. Grand Rapids: Reformation Heritage Books, pp. 56-72. TRINDADE, H. 2004. "Institucionalização e internacionalização das ciências sociais na América Latina em questão. In: Almeida, A. et al. Circulação internacional e formação intelectual das elites brasileiras. Campinas: Ed. da Unicamp, pp. 145-166.

VILHENA, L. R. 1997. Projeto e Missão. O Movimento Folclórico Brasileiro, 1947-1964. Rio de Janeiro: Funarte/Fundação Getúlio Vargas.

WESTPHALEN, C. 1988. Faculdade de Filosofia, Ciências e Letras do Paraná - 50 anos. Curitiba: SBPH - PR. 


\section{TRAJETÓRIAS INTELECTUAIS MARCADAS ENTRE A CIÊNCIA E A RELIGIÃo: JOSÉ LOUREIRO FERNANDES E A FACULdAdE DE FILOSOFIA, CIÊNCIAS E LE- TRAS DO PARANÁ}

Resumo: O presente artigo tem o objetivo de discutir as dinâmicas de funcionamento da rede de intelectuais paranaenses da Faculdade de Filosofia, Ciências e Letras do Paraná (1938-1972) ligados ao catolicismo. Para cumprir esse objetivo, são tomados como eixo alguns elementos da trajetória pessoal e acadêmica de José Loureiro Fernandes, catedrático de Antropologia da instituição. Uma leitura atenta das fontes que nos informam acerca das dinâmicas da relação entre Loureiro Fernandes e outros intelectuais dessa rede, e acerca dos projetos intelectuais e políticos por eles implementados, permite que nos aproximemos da complexidade do universo social da FFCLPR. A partir desses materiais, perscrutamos os diferentes modos pelos quais alguns dos membros dessa rede operaram com os saberes científicos e com os projetos e saberes da Igreja Católica. Essa análise nos fornece indicativos que podem permitir repensar de modo mais amplo os processos sociais envolvidos na constituição das instituições culturais e universitárias brasileiras na primeira metade do século XX.

Palavras-chave: Intelectuais-Brasil, Intelectuais-Paraná, Faculdade de Filosofia, Ciências e Letras do Paraná, José Loureiro Fernandes (1903-1977), trajetórias intelectuais

\section{JOSÉ LOUREIRO FERNANDES AND THE FACULTY OF PHILOSOPHY, SCIENCES AND LETTERS OF PARANÁ: INTELLECTUAL TRAJECTORIES BETWEEN SCIENCE AND RELIGION}

Abstract: This article focusses on the network of intellectuals from the Faculty of Philosophy, Sciences and Letters of Paraná (1938-1972) linked to Catholicism. The personal and academic trajectory of José Loureiro Fernandes, professor of Anthropology of this institution, is used as axis to this discussion. A close reading of the sources that inform us about the dynamics of the relationship between Loureiro Fernandes and other intellectuals of this network, and about the intellectual and political projects they implement, allows us to approach the complexity of the social universe of FFCLPR. These sources offer a new perspective at the different ways in which some of the members of this network operated intellectually with the scientific knowledge and with the projects and the philosophy of the Catholic Church. This analysis may allow a broader rethinking of the social processes involved in the constitution of Brazilian cultural institutions and Universities in the first half of the twentieth century. Keywords: Intellectuals-Brazil, Intellectuals-Paraná, Faculty of Philosophy, Sciences and Letters of Paraná, José Loureiro Fernandes (1903-1977), intellectual trajectories

RECEBIDO: $16 / 04 / 2018$

APROVADO: $21 / 04 / 2018$ 
138 CAMPOS V.18(1-2), 2017 